\title{
Rapid decrease in tumor perfusion following VEGF blockade predicts long-term tumor growth inhibition in preclinical tumor models
}

\author{
Alexandra Eichten · Alexander P. Adler · Blerta Cooper • \\ Jennifer Griffith · Yi Wei · George D. Yancopoulos • \\ Hsin Chieh Lin · Gavin Thurston
}

Received: 19 June 2012/ Accepted: 23 November 2012/Published online: 13 December 2012

(C) The Author(s) 2012. This article is published with open access at Springerlink.com

\begin{abstract}
Vascular endothelial growth factor (VEGF) is a key upstream mediator of tumor angiogenesis, and blockade of VEGF can inhibit tumor angiogenesis and decrease tumor growth. However, not all tumors respond well to anti-VEGF therapy. Despite much effort, identification of early response biomarkers that correlate with long-term efficacy of anti-VEGF therapy has been difficult. These difficulties arise in part because the functional effects of VEGF inhibition on tumor vessels are still unclear. We therefore assessed rapid molecular, morphologic and functional vascular responses following treatment with aflibercept (also known as VEGF Trap or ziv-aflibercept in the United States) in preclinical tumor models with a range of responses to anti-VEGF therapy, including Colo205 human colorectal carcinoma (highly sensitive), C6 rat glioblastoma (moderately sensitive), and HT1080 human fibrosarcoma (resistant), and correlated these changes to long-term tumor growth inhibition. We found that an overall decrease in tumor vessel perfusion, assessed by dynamic contrast-enhanced ultrasound (DCE-US), and increases in tumor hypoxia correlated well with long-term tumor growth inhibition, whereas changes in vascular gene expression and microvessel density did not. Our findings support previous clinical studies showing that decreased tumor perfusion after anti-VEGF therapy (measured by DCE-US) correlated with response. Thus, measuring tumor perfusion changes shortly after treatment with VEGF inhibitors, or possibly other anti-angiogenic therapies, may be useful to predict treatment efficacy.
\end{abstract}

A. Eichten · A. P. Adler · B. Cooper · J. Griffith · Y. Wei ·

G. D. Yancopoulos · H. C. Lin · G. Thurston $(\bowtie)$

Regeneron Pharmaceuticals Inc, 777 Old Saw Mill River Road,

Tarrytown, NY 10591, USA

e-mail: gavin.thurston@ regeneron.com
Keywords VEGF blockade - Tumor perfusion - Tumor growth response $\cdot$ Preclinical model $\cdot$ Response biomarker

\section{Introduction}

Vascular endothelial growth factor (VEGF) plays a key role in physiological and pathological angiogenesis, including tumor angiogenesis [1]. Therefore, a number of agents that inhibit VEGF signaling have been developed and tested in clinical trials [2, 3]. Bevacizumab, a VEGF specific antibody that prevents receptor binding and activation, slowed tumor progression and provided survival benefits in several human tumor types when used in combination with chemotherapy. In addition, several small molecule inhibitors of VEGF receptor tyrosine kinase activity provided benefit in various cancers [4-6]. In preclinical models, VEGF inhibition results in reduced tumor growth, decreased microvessel density (MVD) and normalization of tumor vessel morphology in a wide range of tumor types [7, 8]. Similar MVD reductions were also reported in clinical studies of colorectal tumors sampled shortly after bevacizumab treatment [9].

Despite clear evidence for tumor vessel loss following VEGF inhibition, the functional consequences on tumor blood flow and oxygenation are not entirely clear. Naïvely, one might expect that vessel loss would result in decreased tumor perfusion. However, more detailed considerations suggested the opposite, namely, that tumor vessel pruning and "normalization" may lead to decreased intra-tumoral pressure, increased tumor perfusion, and consequently decreased tumor hypoxia [10]. Indeed, some preclinical studies indicate increased tumor perfusion after VEGF blockade [11, 12]. In contrast, other studies have reported increased tumor hypoxia and decreased perfusion in 
preclinical models and non-small cell lung cancer (NSCLC) patients [13-15]. Thus, the functional consequences of antiVEGF therapy are not clear, even in preclinical tumor models.

To add to the complexity, not all tumors within a given tumor type respond equally well to anti-VEGF therapy. For example, in glioblastoma patients treated with a small molecule kinase inhibitor (cediranib), approximately $60 \%$ of tumors displayed changes in dynamic contrast-enhanced magnetic resonance imaging (DCE-MRI) signals indicative of a response to anti-VEGF therapy, whereas the remaining $40 \%$ did not [16]. Despite much effort, predicting which tumors will respond to anti-VEGF therapy, or how longterm tumor growth response is related to vascular changes, has been difficult. For instance, it is unknown whether tumors with the largest MVD reduction show the greatest tumor growth inhibition (TGI). Further, tumor vessel features rendering them sensitive, or resistant, to VEGF inhibition are not well understood. Ultimately, predictive biomarkers based on mechanistic differences in tumor cells and tumor blood vessels are needed.

To begin to address these issues, we characterized initial responses of tumor vessels to VEGF blockade in preclinical tumors with a range of responses to anti-VEGF therapy (sensitive, moderately responsive, and resistant). For these studies, we used aflibercept (also known as VEGF Trap or ziv-aflibercept in the United States), a recombinant fusion protein that potently binds all isoforms of human and murine VEGF-A, VEGF-B and Placental Growth Factor (PlGF). Tumor bearing mice were treated with aflibercept, and tumors were analyzed for rapid (within 3 days) changes in molecular (gene expression), morphologic (MVD) and functional (vascular perfusion, tumor hypoxia) tumor vessel properties. These changes were then compared to aflibercept-mediated longer-term tumor growth effects. Using this approach, we observed that functional changes correlated well with the overall level of TGI, whereas molecular or morphological changes showed a poor correlation. These findings suggest that changes in functional parameters, such as tumor perfusion and hypoxia, may be good predictors of long term growth inhibition.

\section{Materials and methods}

In vivo tumor studies

Animal studies were performed in accordance with Regeneron's Institutional Animal Care and Use Committee guidelines. Tumor cells were obtained from the American Type Culture Collection (ATCC), except for the PC3 M line, which was obtained from the NCI, DCT Tumor Repository, NCI-FCRF, Frederick, MD. $1 \times 10^{6}$ Colo205 human colon carcinoma, $1 \times 10^{6} \mathrm{C} 6$ rat glioblastoma, $2 \times 10^{6}$ HT1080 human fibosarcoma, $1 \times 10^{6}$ A431 human squamous cell carcinoma, $1 \times 10^{6} 786-0$ human renal cell carcinoma, $5 \times 10^{5}$ MMT murine mammary carcinoma, $1 \times 10^{6}$ PC-3 M metastasis-derived variant of human prostate adenocarcinoma PC-3 and $1 \times 10^{6}$ LLC murine Lewis lung carcinoma cells were grown s.c. in male CB.17/SCID mice (Taconic). When tumors reached approximately $100 \mathrm{~mm}^{3}$, mice were treated by s.c. injection with $\mathrm{hFc}$ (control protein, $25 \mathrm{mg} / \mathrm{kg}$ ) or a maximally effective anti-tumor dose of aflibercept [17] (VEGF Trap, zivaflibercept, $25 \mathrm{mg} / \mathrm{kg}$ ) (\# mice per treatment group: $\mathrm{n}=5-7$ tumor growth; $\mathrm{n}=4-5$ IHC; $\mathrm{n}=3-4$ TaqMan; $\mathrm{n}=8-24$ micro-ultrasound; $\mathrm{n}=5-10$ FITC-lectin flow cytometry). For long-term studies treatments occurred $2 \times$ per week. Mice were monitored for tumor growth and overall health. HypoxyProbe-1 (Chemicon; $60 \mathrm{mg} / \mathrm{kg}$ ) was injected i.p. $1 \mathrm{~h}$ prior to sacrifice. Tumors were harvested: $\sim 1 / 2$ tumor in $4 \%$ paraformaldehyde, a cross-section in OCT, $\sim 1 / 2$ tumor in RNAlater. \% Tumor Growth Inhibition (TGI) was calculated as follows: $\left[1-\left(\left(\mathrm{T}_{\text {final }}-\mathrm{T}_{\text {initial }}\right) /\left(\mathrm{C}_{\text {final }}-\mathrm{C}_{\text {initial }}\right)\right)\right]^{*} 100$, where $\mathrm{T}=$ aflibercept-treated tumor volumes and $\mathrm{C}=$ control-treated tumor volumes at treatment start and after 10-14 day treatment (10 days: LLC, MMT; 14 days: HT1080, Colo205, C6, A431, 786-0, PC-3 M). Tumor growth curves are presented as mean \pm standard error of the mean (SEM).

Immunohistochemistry and image analysis

IHC on gelatin embedded tissue sections: Tissues were fixed in $4 \%$ paraformaldehyde for $72 \mathrm{~h}$ and embedded in a $4 \%$ gelatin/PBS solution. Gelatin blocks were fixed in $4 \%$ paraformaldehyde overnight at $4{ }^{\circ} \mathrm{C}$, then transferred into a $30 \%$ sucrose/PBS solution at $4{ }^{\circ} \mathrm{C}$ until the blocks sunk ( $\sim 72 \mathrm{~h}$ ). Tissue was cut into $80 \mu \mathrm{m}$ sections, which were stored in cryoprotectant (1\% Polyvinylpyrrolidone, $30 \%$ glycerol, and $30 \%$ sucrose in NaPBS) at $-20{ }^{\circ} \mathrm{C}$ until further use. For IHC detection of CD31 and HypoxyProbe (pimonidazole), sections were treated as follows: $30 \mathrm{~min}$ in $0.3 \% \mathrm{H}_{2} \mathrm{O}_{2}$ at $4{ }^{\circ} \mathrm{C}, 2 \mathrm{~h}$ in blocking solution (CD31: $0.3 \%$ Triton X100/4 \% normal rabbit serum/1 \% BSA/PBS; HypoxyProbe: $0.3 \%$ Triton X100/4 \% normal horse serum $/ 1 \% \mathrm{BSA} / \mathrm{PBS}$ ) at RT followed by an overnight incubation at $4{ }^{\circ} \mathrm{C}$ with rat anti-murine CD31 Ab (1:150; BD; MEC13.3) or a mouse anti-HypoxyProbe-1 antibody $(1: 1,000$; Chemicon) diluted in the respective blocking solution containing $1 \%$ serum. After five 3 min washes in PBS, CD31 was detected with a biotinylated mouseadsorbed rabbit anti-rat antibody (1:150; Vector Laboratories;) and HypoxyProbe was detect with a biotinylated horse anti-mouse antibody (1:500; Vector Laboratories;) in a $2 \mathrm{~h}$ incubation at RT. Sections were subjected to an ABC 
reaction according to the manufacturers recommendations (Vector Laboratories; ABC VectaStain Elite) for $1 \mathrm{~h}$ at RT diluted in $1 \%$ BSA in $50 \mathrm{mM}$ PBS. After five $3 \mathrm{~min}$ washes in PBS, antigens were revealed with 3,3'-diaminobenzidine (DAB, Sigma).

OCT embedded tumors were cut into $30 \mu \mathrm{m}$ frozen sections. Tissue was air dried, $10 \mathrm{~min}$ fixed in acetone $\left(-20{ }^{\circ} \mathrm{C}\right)$, avidin-biotin blocked (Vector), blocked in $2.5 \%$ normal goat serum $/ 1 \% \mathrm{BSA} / \mathrm{PBS}$ for 30-45 min (RT), incubated for $16 \mathrm{~h}$ at $4{ }^{\circ} \mathrm{C}$ with rat anti-murine $\mathrm{CD} 31 \mathrm{Ab}(1: 50$; $\mathrm{BD})$ diluted in $0.5 \times$ block followed by a $45 \min (\mathrm{RT})$ incubation with a biotinylated anti-rat antibody (1:150; Vector). Antigens were revealed with 3,3'-diaminobenzidine (DAB, Sigma).

For analysis photomicrographs were acquired at $2.5 \times$ magnification. Vessel density and hypoxia area were determined using NIH image software as previously described [18].

RNA preparation and TaqMan analysis

Total RNA was purified using RNeasy (Qiagen). RNA quality and concentration were evaluated using a spectophotometer (NanoDrop ND-1000). cDNA was synthesized using $1 \mu \mathrm{g}$ of total RNA and High Capacity RNA to cDNA Mastermix Kit (ABI). Expression of various genes was normalized to cyclophilin expression. TaqMan primer and probe sequences are as follows:
( $1 \mu \mathrm{g} / \mathrm{ml}$; Invitrogen) was used to exclude dead cells. Data acquisition: Beckman-Coulter MoFlo Legacy; data analysis: FlowJo software (Tree Star). Data shown represent mean \pm standard error of the mean (SEM).

Dynamic contrast-enhanced micro-ultrasound (DCE-micro US)

Animals were anaesthetized (isofluorane $(3.0 \%)$ /medical air mixture), secured to heated platform and dehaired. Ultrasound gel (Aquasonic, Parker Laboratories) provided coupling interface between ultrasound probe and animal. Image acquisition: Vevo2100 micro-ultrasound imaging system (VisualSonics); contrast agent: MicroMarker $^{\mathrm{TM}}$ (microbubbles, VisualSonics). Contrast agent was prepared with a final concentration of $2 \times 10^{9}$ microbubbles $/ \mathrm{ml}$ saline and a $50 \mu \mathrm{l}$ bolus was delivered via tail vein catheter during image acquisition. Quantification of relative blood volume, which represents tumor perfusion, was determined by analysis of a 2D area representing the largest tumor cross-section (Vevo2100 analysis software).

Statistical analyses

Statistical analyses were performed using Prism software. Specific test include 2-way ANOVA with Bonferroni post

\begin{tabular}{llll}
\hline Gene & Forward primer & Reverse primer & Probe sequence \\
\hline$m$ Kcne 3 & AGACCTGGTACATGAGCCTCCAT & CAAGTGACTGTGAAGGGTTGTGTT & TGGGCAGTCTCATCCT \\
$m$ Nid 2 & CCGCTGTGGCCCTAATTCT & TGCGGCATTCACACCTGTA & TGTGTGTCAACTTGGTGGG \\
$m$ Cdh5 & AATCGGGAGCATGCCAAGT & TGGGCACCCCGTTGTC & CCCGTGCTCATCTC \\
$m$ Tiel & AGCCTGAGCCCTTGAGTTACC & AAAGTTGCCCTCCCTATGAG & TGGGAGGACATCACC \\
$m$ Robo 4 & GCTAGGCGCTTTCCATCCA & GCGGCTGCAGAGACTATCTGA & TTGGCTGGAACCTC \\
$m$ Esm 1 & TCTGGACTTTCCCTTCTTCCAG & CTGTGTGGGAGGCAGAGGTC & TGCAGCAGCCAAATCTCCCAGCA \\
$m$ VegfA & GTATGGCTGGCTGGGTCACT & GTTTGATCCGCATGATCTGTAGAG & ACCACTGTGATCTGC \\
$m$ Cyclophilin & CGTGGGCTCCGTCGTC & CCCTTCTTCTTATCGTTGGCC & TTGCTGCCCGGACCCTCCG \\
\hline
\end{tabular}

Flow cytometry

Tumor bearing mice (C6 or HT1080 tumors, $100 \mathrm{~mm}^{3}$ ), or nontumor control mice, were treated s.c. with $\mathrm{hFc}$ (control protein, $25 \mathrm{mg} / \mathrm{kg}$ ) or aflibercept (VEGF Trap, $25 \mathrm{mg} / \mathrm{kg}$ ) $24 \mathrm{~h}$ prior to tissue harvest. To label endothelial cells of functional vessels, mice were i.v. injected with FITC-conjugated Lycopersicon esculentum (tomato) lectin ( $2.0 \mathrm{mg} / \mathrm{ml}$; Vector) $3 \mathrm{~min}$ prior to tissue harvest. Single cell suspensions were prepared from normal skin ( $\mathrm{n}=4, \mathrm{n}=2$ no FITC-lectin), C6 tumors ( $\mathrm{n}=7$ control or aflibercept, $\mathrm{n}=4$ no FITC-lectin) or HT1080 tumors ( $\mathrm{n}=7$ control or aflibercept, $\mathrm{n}=3$ no FITC-lectin) as described previously [19] and endothelial cells were detected using a PE-conjugated anti-CD31 Ab (1:200; BD). DAPI hoc test (tumor growth curves), 1-way ANOVA with Bonferroni post hoc test (vessel density, gene expression changes, hypoxia analysis) and Mann-Whitney test (microultrasound analysis). $p$ values $<0.05$ were considered statistically significant.

\section{Results}

Vessel morphology changes in tumors with a range of responses to aflibercept

Based on studies with a wide variety of murine tumor models, three tumors that display a range of responses to 


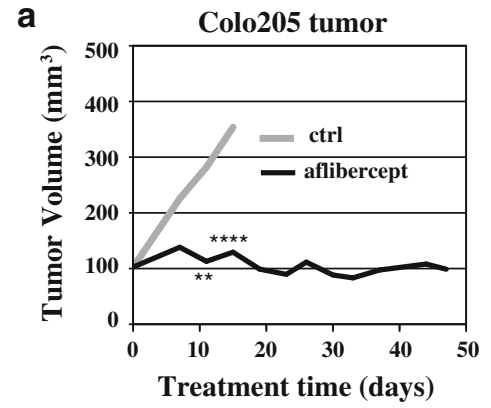

d

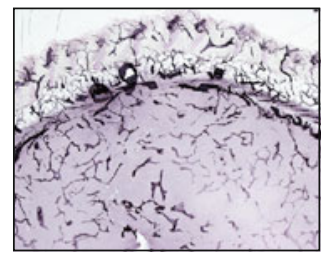

Colo205 - control

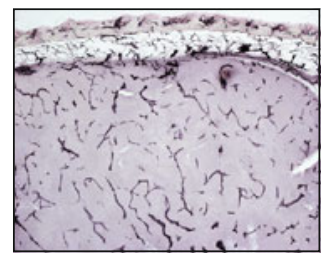

Colo205 - 24h aflibercept

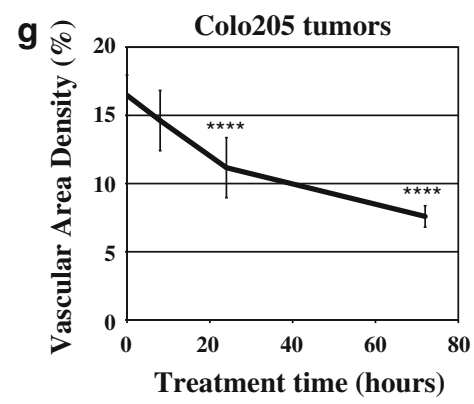

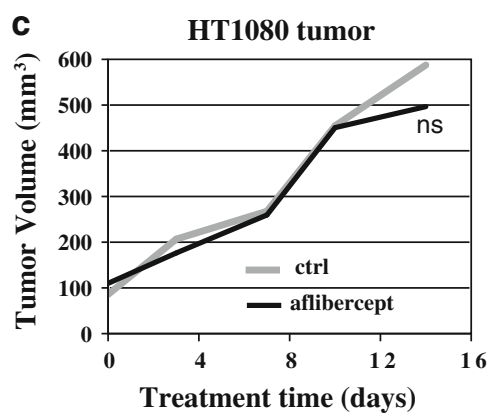

f

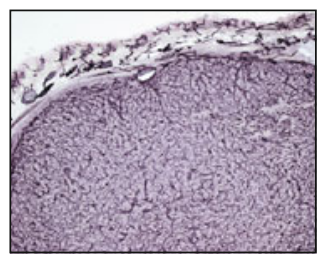

HT1080 - control

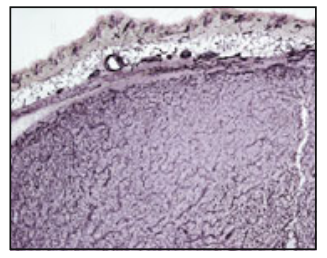

HT1080 - 24h aflibercept

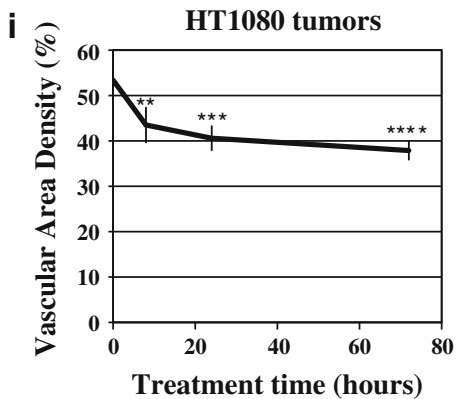

Fig. 1 Tumor growth and vascular response to aflibercept in Colo205, C6 and HT1080 tumors. a-c Colo205, C6 and HT1080 xenografts $(\mathrm{n}=5-7$ each treatment group/tumor type) show different levels of TGI in response to aflibercept treatment (black) compared to control-treated tumors (grey): sensitive Colo205, moderately responsive C6 and resistant HT1080. d-f Representative images of MVD assessed by CD31 IHC in control and $24 \mathrm{~h}$ aflibercept-treated Colo205, C6 and HT1080 tumors $(80 \mu \mathrm{m}$ gelatin sections). gi Quantitative analysis of vessel area density (\%) in control and 8, 24 and $72 \mathrm{~h}$ aflibercept-treated Colo205, C6 and HT1080 tumors

aflibercept were chosen for more detailed study. Colo205 tumors were potently growth inhibited (Fig. 1a), C6 tumors showed an intermediate growth inhibition in response to aflibercept treatment, with an initial growth delay followed by restrained tumor growth (Fig. 1b). In contrast, HT1080 tumors showed no growth inhibition upon aflibercept treatment (Fig. 1c). These differences in tumor response were observed at a saturating dose of aflibercept $(25 \mathrm{mg} / \mathrm{kg}$
( $n=4-5$ each time point/tumor type). All experiments were repeated at least twice; shown is an example experiment $(n=5-7$ for each treatment group (tumor growth data) or $n=4-5$ for each time point (MVD data)). Results shown represent means for tumor growth data and mean \pm standard deviation (SD) for MVD analysis. $P<0.05^{*}$, $<0.01 * *,<0.001 * * *,<0.0001 * * * *$ by 2 way-ANOVA with Bonferroni post hoc test (tumor growth data compared to control treated tumor growth) and by 1 way-ANOVA with Bonferroni post hoc test (MVD, each time point compared to control (0 time point))

twice per week), thus the differences reflect inherent responses to aflibercept and not merely different dose responses.

We investigated the rapid effects of VEGF blockade on the vasculature of these 3 tumor types. As revealed by immunohistochemistry (IHC) for the vessel specific marker CD31 in thick sections, untreated Colo205 and C6 tumors have a significantly lower MVD (17 and $20 \%$, respectively) 
than HT1080 tumors (55 \%) (Fig. 1d-f upper images; g-i time point 0 ). Following aflibercept treatment, MVD rapidly decreased in all tumor types, albeit to varying degrees (Fig. 1d-f lower images; g-i). Quantitative analysis of relative MVD after aflibercept administration in comparison to control-treated tumors revealed that Colo205 tumors lost 11, 32 and $54 \%$ of their vasculature at 8, 24 and $72 \mathrm{~h}$ after treatment, respectively. C6 tumors lost even more vessels (28, 67 and $81 \%$ at 8, 24 and $72 \mathrm{~h}$ after treatment, respectively). Aflibercept resistant HT1080 tumors progressively lost vessels after aflibercept treatment, albeit to a much lesser degree (up to $29 \%$ by $72 \mathrm{~h}$ ), suggesting that the HT1080 tumor vasculature is only partially dependent on VEGF. These results show that blockade of VEGF can cause rapid loss of tumor vascularity, and further, that the vasculature in different xenograft tumors varies in its dependence on ongoing VEGF signaling.

Identification of two phases of gene expression changes in tumor vessels following aflibercept treatment

To determine how morphological tumor vessel changes manifest as molecular changes in gene expression, microarray analysis was performed on RNA from whole tumors treated with aflibercept for 8, 24 and $72 \mathrm{~h}$. Mouse and human genes were assessed separately using mouse and human specific gene chips (custom Agilent microarray). Microarray analysis of mouse (host) genes in different tumors implied a rapid and consistent decrease in expression of a number of genes specific to endothelial cells [20-22] following aflibercept treatment. To confirm and extend the microarray findings, six genes were analyzed for expression changes in Colo205, C6 and HT1080 tumors treated with aflibercept for 8,24 and $72 \mathrm{~h}$ by TaqMan, using primer pairs specific for murine mRNA. Gene expression was normalized to cyclophilin expression (similar results were obtained using GAPDH as a normalization gene; data not shown). Close inspection of these gene expression changes revealed two distinct temporal patterns: 'acute' and 'delayed' response genes. The 'acute' set of genes decreased in expression rapidly after aflibercept treatment $(8 \mathrm{~h}$ ) and remained decreased (Fig. 2a-c, black lines). Further, these 'acute' genes showed a large absolute decrease in expression levels, dropping up to $85 \%$. Among the 'acute' genes were potassium voltagegated channel Isk-related subfamily gene 3 (Kcne3), endothelial cell-specific molecule 1 (Esm1) and nidogen2 (Nid2). Because of their rapid decrease after VEGF blockade (Fig. 2a-c, black lines), these 'acute' genes are likely direct targets of VEGF signaling.

A second set of genes decreased in expression at 24 and $72 \mathrm{~h}$ after aflibercept treatment, but were not yet significantly affected at the $8 \mathrm{~h}$ time point, thus showing a 'delayed' response (Fig. 2a-c, grey lines). Examples of genes that displayed robust 'delayed' changes were roundabout homolog 4 (Robo4), cadherin 5 (Cdh5) and tyrosine kinase with immunoglobulin-like and EGF-like domains 1 (Tie1). Other genes in this category included platelet/endothelial cell adhesion molecule 1 (Pecam1 or CD31) and intercellular adhesion molecule 2 (Icam2) (data not shown), two commonly used IHC endothelial cell markers [23, 24]. Thus, these 'delayed' genes may reflect a decrease in overall tumor vascularity or endothelial cell number. Changes in 'delayed' gene expression and MVD (Fig. 1d-i) appeared to have similar trends in terms of both timing and magnitude of decrease in different tumor types. When the combined expression of the 'delayed' gene changes was overlayed with MVD changes, comparable patterns emerged for each tumor (Fig. 2d-f), suggesting that 'delayed' gene changes can be used as markers for changed MVD in tumors treated with VEGF inhibitors.

Decreased tumor perfusion following treatment with aflibercept

To determine whether VEGF blockade also affected vessel functionality, we assessed tumor vessel perfusion $24 \mathrm{~h}$ after aflibercept administration using contrast-enhanced microultrasound. Analysis of 2-dimensional (2D) ultrasound data revealed that perfusion of Colo205 and C6 tumors decreased by 32 and $59 \%$, respectively (Fig. 3a, b, d, e). In comparison, HT1080 tumor perfusion was not decreased at $24 \mathrm{~h}$ after aflibercept treatment (Fig. 3c, f). Interestingly, although HT1080 tumors have a dramatically higher baseline MVD (55\%; Fig. 1i) than C6 (20\%; Fig. 1h) or Colo205 tumors (17\%; Fig. 1g), baseline perfusion in the three tumor types was comparable (relative contrast intensity values of 8-10; Fig. 3d-f, control), as was previously shown for other tumor types [25]. These data suggest that a smaller fraction of vessels are well perfused in HT1080 tumors compared to C6 or Colo205 tumors.

To further compare the relative amounts of perfused vessels in C6 and HT1080 tumors, vessel perfusion was assessed by another method, namely i.v. injection of FITC-conjugated Lycopersicon esculentum tomato lectin (FITC-lectin), which binds to the luminal surface of blood endothelial cells (BECs, defined as CD31 positive) in functionally perfused vessels. Following in vivo labeling, the proportion of endothelial cells in the tumor and normal skin, and the fraction of endothelial cells labeled by FITC-lectin were both assessed by flow cytometry. For reference, BECs from normal skin comprise $1.9 \%$ of all skin cells, and $96 \%$ of the BECs in normal skin were labeled by FITC-lectin (Fig. 3g, skin). As a further control, the same proportion of BECs were found in skin and tumors of mice that were injected with FITC-lectin versus those that were not injected, 
Fig. 2 Gene expression analysis revealed two phases of gene expression changes in tumor vessels following aflibercept treatment. a-c Gene changes (TaqMan) upon VEGF blockade occur in two distinct patterns: 'acute' gene changes occur in Kcne3, Esm1 and Nid2 (black), while 'delayed' gene changes occur in Tie1, Cdh5 and Robo4 (grey) in Colo205, C6 and HT1080 tumors after 8, 24 and $72 \mathrm{~h}$ aflibercept treatment $(n=3-4$ each time point/tumor type) $\mathbf{d}-\mathbf{f}$ Averages of MVD changes (grey) and averages of 'delayed' gene expression changes (black) show a corresponding pattern in Colo205, C6 and HT1080 tumors after 8, 24 and $72 \mathrm{~h}$ aflibercept treatment. All experiments were repeated at least twice; shown is an example experiment for TaqMan data $(n=3-4$ for each time point). Results shown represent means or mean \pm standard deviation (SD). $P<0.05^{*},<0.01^{* *}$, $<0.001 * * *,<0.0001 * * * *$ by 1 way-ANOVA with Bonferroni post hoc test (TaqMan data, each time point compared to control (0 time point)) a

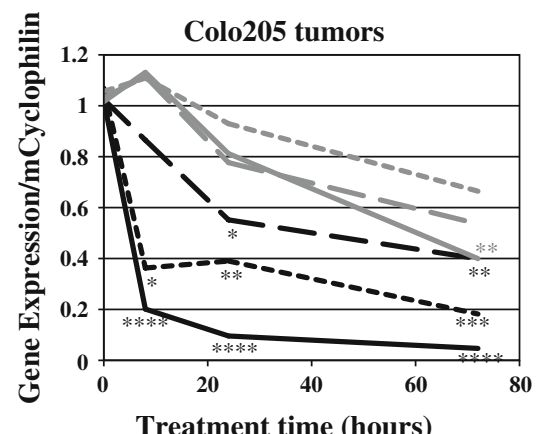

Treatment time (hours)

C

:

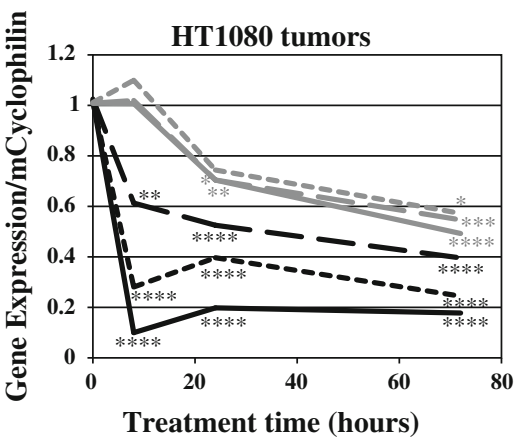

d
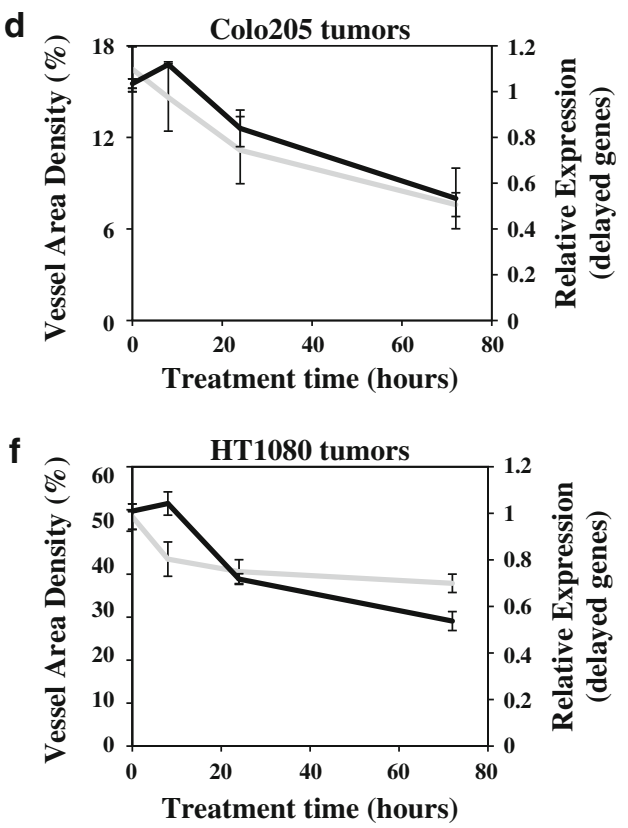

b
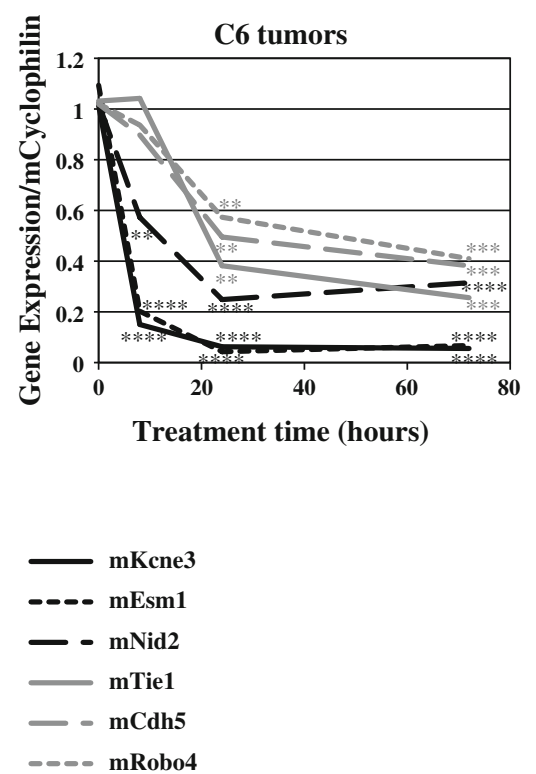

e

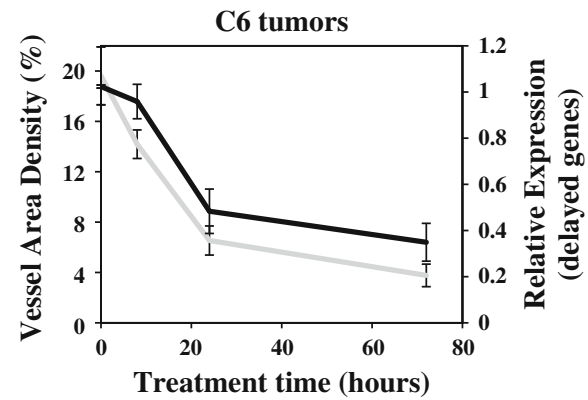

vessel density
delayed gene expression but virtually no BECs were found to be positive for FITClectin in non-injected mice (Fig. 3g).

The number of BECs in untreated C6 tumors $(0.8 \%$ of total cells) was significantly less than in HT1080 tumors (2.2\%) (Fig. 3g). Of the BECs in untreated C6 tumors, approximately $55 \%$ were perfused (i.e., positive for FITClectin). In contrast, only $18 \%$ of the BECs in untreated HT1080 tumors were perfused (Fig. 3g; Table 1). Thus, despite more than a twofold difference in total BEC, the fraction of BECs labeled by intravascular lectin
(FITC-positive BECs) was similar in C6 and HT1080 tumors ( 0.40 vs. $0.43 \%$ of total cells, respectively). This finding corroborates our micro-ultrasound findings that untreated C6 and HT1080 tumors have similar levels of perfusion as measured by micro-ultrasound (Fig. 3e, f, control), despite dramatically different MVD (Fig. 1i, h, control).

Treatment with aflibercept $(24 \mathrm{~h})$ decreased the number of BECs in C6 tumors to $0.5 \%$ of total cells $(\sim 37 \%$ decrease) and to $1.6 \%$ in HT1080 tumors ( $28 \%$ decrease) (Fig. 3g, h; Table 1). These data correspond with 
a

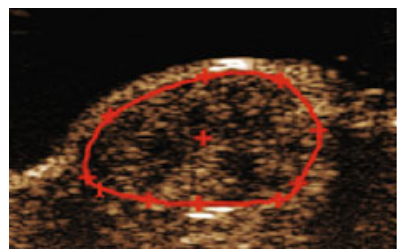

Colo205 - control

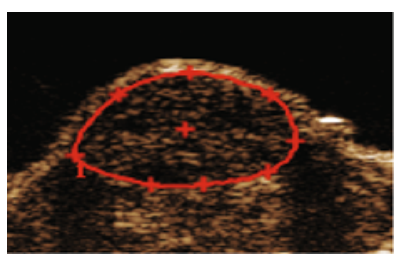

Colo205 - 24h aflibercept

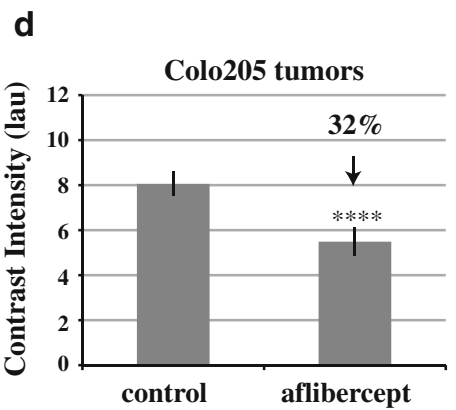

b

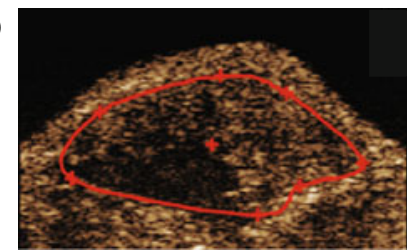

C6 - control

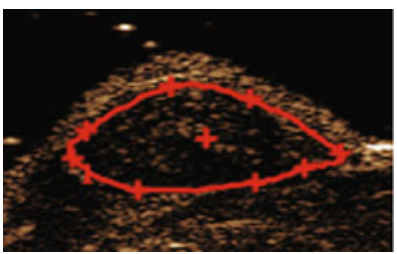

C6 - 24h aflibercept

e

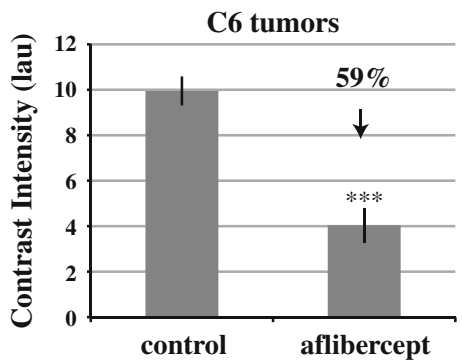

C

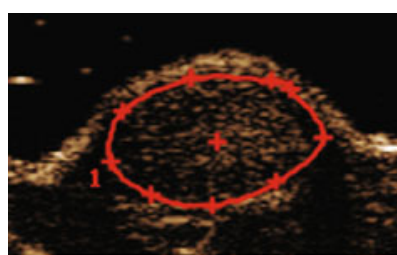

HT1080 - control

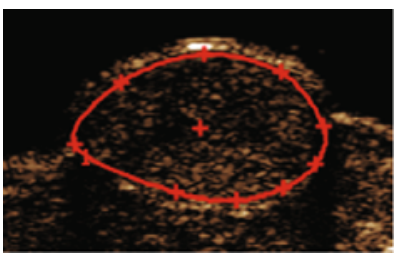

HT1080 - 24h aflibercept

f

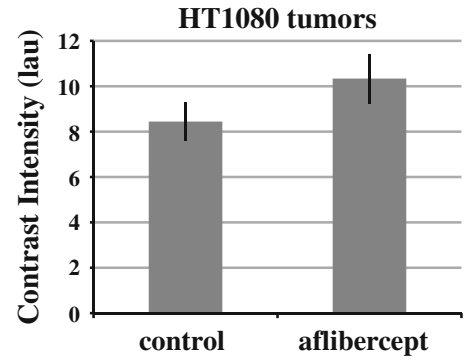

g

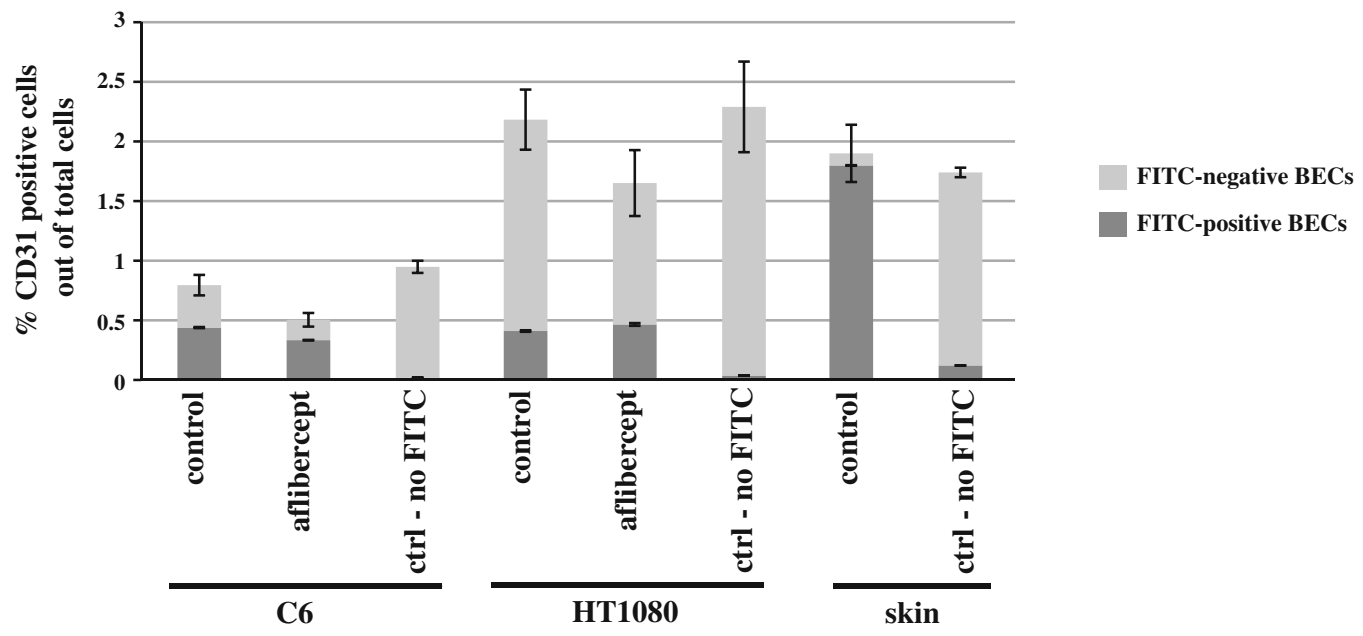

Fig. 3 Perfusion decreased in response to aflibercept treatment in Colo205 and C6 tumors, but remained unchanged in HT1080 tumors. ac Representative images of vessel perfusion assessed by 2-dimensional (2D) DCE-US in control and $24 \mathrm{~h}$ aflibercept-treated Colo205, C6 and HT1080 tumors. Tumors are outlined in red. $\mathbf{d}-\mathbf{f}$ Quantitative analysis of vessel perfusion in control and $24 \mathrm{~h}$ aflibercept-treated Colo205 ( $\mathrm{n}=18$ and 24 , respectively), C6 ( $\mathrm{n}=8$ and 12 , respectively) and HT1080 tumors ( $\mathrm{n}=12$ and 9, respectively) $\mathrm{g}$ Flow cytometry analysis of CD31positive blood vessel endothelial cells (BECs) in combination with the intravenously injected perfusion marker FITC-lectin in control and $24 \mathrm{~h}$

the relative decrease in MVD after aflibercept treatment (Fig. 1h, i; Table 1). After $24 \mathrm{~h}$ of aflibercept treatment, the proportion of FITC-lectin positive BEC in C6 tumors aflibercept-treated C6 $(\mathrm{n}=10$ each treatment group; $\mathrm{n}=5$ for 'no-FITC' group) and HT1080 tumors $(\mathrm{n}=10$ each treatment group; $\mathrm{n}=5$ for 'no-FITC' group) as well as control-treated skin tissue $(\mathrm{n}=5$ each group). Shown are perfusion and flow cytometry results combined from multiple experiments. Results shown represent mean \pm standard error of the mean (SEM). $P<0.05^{*},<0.01^{* *},<0.001^{* * *},<0.0001^{* * * *}$ by Mann-Whitney test (tumor perfusion). Differences between FITC-lectin positive BECs in ctrl versus aflibercept treated C6 or HT1080 tumors and between ctrl treated C6 and ctrl treated HT1080 tumors were not statistically significant by Mann-Whitney test

increased slightly to $66 \%$ of all BECs, although the total number of FITC-lectin positive BECs went down (to $0.33 \%$ of total cells). In HT1080 tumors after aflibercept 
Table 1 Flow cytometry analysis of all CD31-positive blood vessel endothelial cells (BECs) and perfused (FITC-lectin positive) BECs derived from control and $24 \mathrm{~h}$ aflibercept-treated C6 and HT1080 tumors

\begin{tabular}{|c|c|c|c|c|c|c|c|c|}
\hline & \multicolumn{2}{|c|}{$\begin{array}{l}\% \mathrm{CD} 31+(\mathrm{BEC}) \text { cells out of } \\
\text { total cells }\end{array}$} & \multirow[t]{2}{*}{$\begin{array}{l}\text { Relative } \\
\text { change }(\%)\end{array}$} & \multicolumn{2}{|c|}{$\begin{array}{l}\% \text { FITC-lectin }+ \text { BECs out of } \\
\text { total cells }\end{array}$} & \multirow[t]{2}{*}{$\begin{array}{l}\text { Relative } \\
\text { change }(\%)\end{array}$} & \multicolumn{2}{|c|}{$\begin{array}{l}\% \text { FITC-lectin }+ \text { BECs out of } \\
\text { total BECs }\end{array}$} \\
\hline & Control & Aflibercept & & Control & Aflibercept & & Control & Aflibercept \\
\hline C6 & 0.8 & 0.5 & -37 & 0.43 & 0.33 & -24 & 55 & 66 \\
\hline HT1080 & 2.2 & 1.6 & -28 & 0.4 & 0.48 & +20 & 18 & 31 \\
\hline
\end{tabular}

treatment, the proportion of FITC-lectin positive BEC also increased slightly to $31 \%$ of all BECs, whereas the total number of BECs increased slightly (to $0.48 \%$ of all cells) (Fig. 3g; Table 1). Again, these findings are consistent with perfusion changes seen by micro-ultrasound following treatment of these tumors with aflibercept (Fig. 3e, f). Thus, this flow cytometry-based analysis of tumor vessel perfusion provides a powerful link between functional perfusion assays and immunohistochemistry of tumor blood vessels following anti-VEGF treatment.

Increased tumor hypoxia following treatment with aflibercept

To determine whether the decreased tumor perfusion following aflibercept treatment resulted in tumor oxygenation changes, we analyzed hypoxia in Colo205, C6, and HT1080 tumors at 8, 24 and $72 \mathrm{~h}$ after aflibercept treatment. Hypoxia was assessed by HypoxyProbe IHC (Fig. 4a-c) as well as by analyzing the expression of VEGF, a hypoxia regulated gene (Fig. 4g-i). Colo205 and C6 tumors have hypoxic regions even under baseline conditions, which become more pronounced upon aflibercept treatment starting at $8 \mathrm{~h}$ (Fig. $4 \mathrm{a}, \mathrm{b}, \mathrm{d}, \mathrm{e}$ ). The increase in HypoxyProbe staining observed in C6 and Colo205 tumors after $24 \mathrm{~h}$ aflibercept treatment (Fig. 4d, e) corresponded with decreased perfusion (Fig. 3d, e). In comparison, HT1080 tumors had little or no hypoxic regions at baseline, and no increase in hypoxia at $72 \mathrm{~h}$ of treatment with aflibercept (Fig. 4c, f), consistent with the unchanged tumor perfusion (Fig. 3c, f). Similarly, expression of VEGF progressively increased in C6 and Colo205 tumors, whereas VEGF expression was unchanged in HT1080 tumors (Fig. 4g). Taken together, increased tumor hypoxia correlated with decreased tumor perfusion.

Tumor perfusion changes correlated with long-term response to aflibercept

The results from our analysis of three tumor types suggested that rapid changes in tumor perfusion and/or hypoxia correlated better with long-term tumor growth response to aflibercept than did other parameters such as changes in microvessel density or vascular gene expression (Fig. 5a). To further assess whether tumor vascular perfusion changes at $24 \mathrm{~h}$ after aflibercept treatment correlated with long-term growth inhibition, we extended our analyses to several additional tumor types (A431, 786-0, MMT, LLC and PC-3 M) grown in immunocompromised SCID mice. We also included a syngeneic model, LLC tumors grown in C57B16 mice, to assess the effects of aflibercept on tumor perfusion and growth in immunocompetent mice. As expected, tumor growth inhibition in immunocompromised mice did not correlate well with changes in tumor vessel density (Fig. $5 b, \mathrm{R}^{2}=0.09$ ). In comparison, in this larger sample including one syngeneic model, tumor growth inhibition showed a correlation with changes in tumor perfusion (Fig. $5 c, R^{2}=0.73$ ).

\section{Discussion}

The search for early response and predictive biomarkers of tumor response to anti-angiogenic agents has so far not provided definitive candidates. While clinical studies have sought such markers by sampling numerous growth factors and cytokines, preclinical studies may be able to provide more mechanism-based candidates and approaches. In this study, we analyzed several tumors with a wide range of longterm tumor growth responses to anti-VEGF therapy. Using subcutaneous tumor models, we correlated early morphologic and functional vascular changes following treatment with aflibercept to long-term tumor growth inhibition (TGI). We found that changes in tumor hypoxia and perfusion correlated with long-term TGI, whereas changes in vascular gene expression and MVD showed a poor correlation.

In early clinical analyses, MVD was proposed as a prognostic indicator for disease stage, likelihood of metastasis, recurrence, and survival in a range of tumor types [26-28]. To date, however, neither baseline values, nor treatment-related changes in MVD have proven useful for evaluating or guiding anti-angiogenic treatments [29]. To extend the analysis of MVD, we identified a set of endothelial cell marker genes, including Tie1, Pecam1, Cdh5, Icam2 and Robo4 [20-22], which decreased following treatment with aflibercept. The timing and 


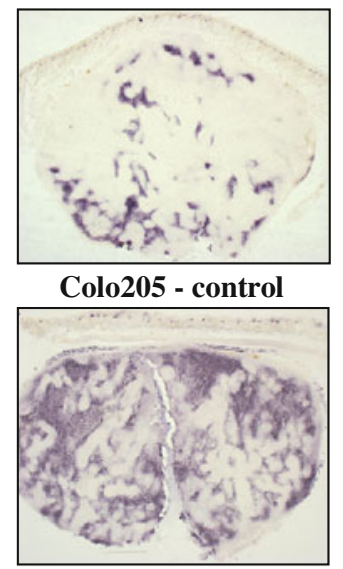

Colo205 - 24h aflibercept

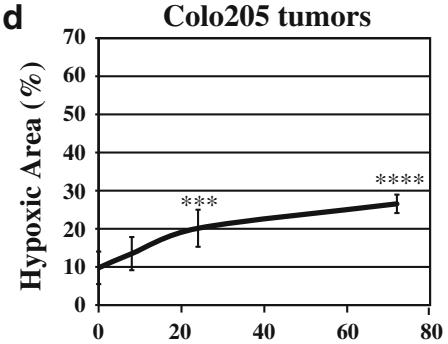

Treatment time (hours)

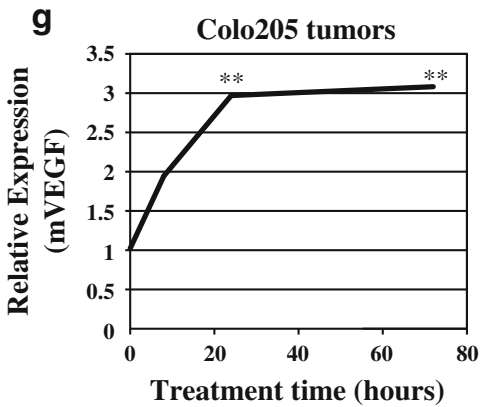

b

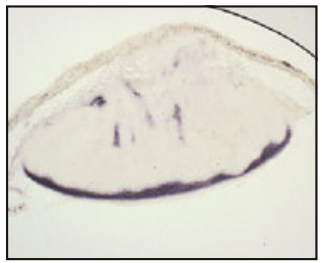

C6 - control

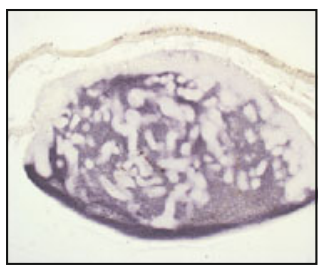

C6 - 24h aflibercept

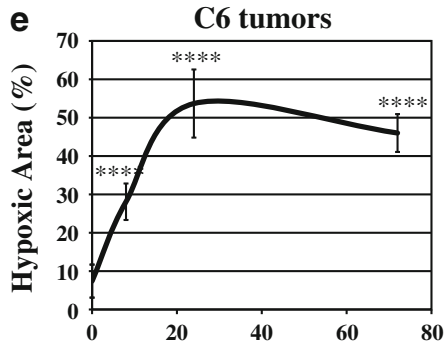

Treatment time (hours)

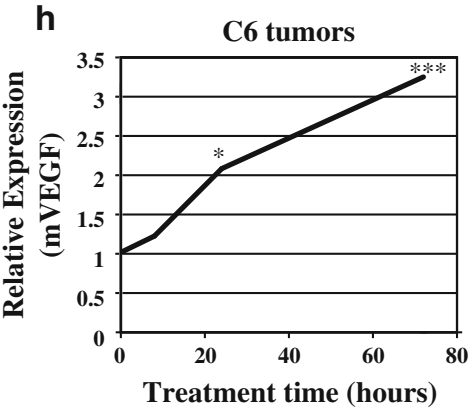

C

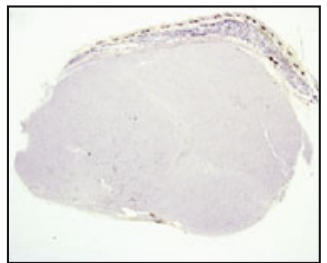

HT1080 - control

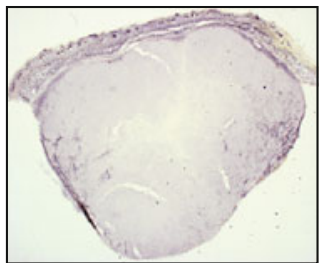

HT1080 - 24h aflibercept

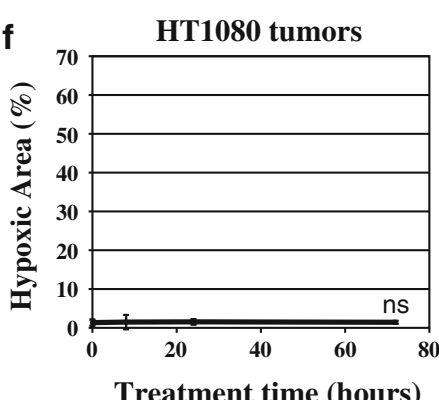

Treatment time (hours)

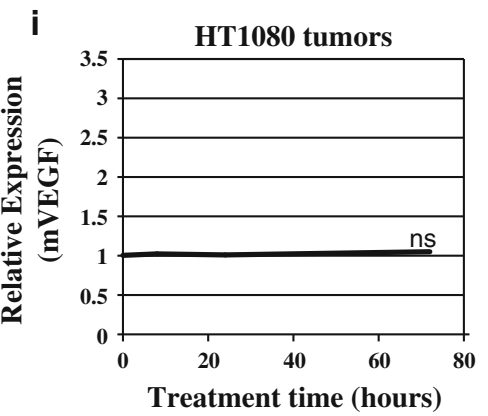

Fig. 4 Tissue oxygenation decreased in response to aflibercept treatment in Colo205 and C6, but not in HT1080 tumors. ac Representative images of hypoxia assessed by HypoxyProbe IHC in control and $24 \mathrm{~h}$ aflibercept-treated Colo205, C6 and HT1080 tumors ( $80 \mu \mathrm{m}$ gelatin sections). d-f) Quantitative analysis of hypoxia area (\%) in control and 8, 24 and $72 \mathrm{~h}$ aflibercept-treated Colo205, C6 and HT1080 tumors ( $\mathrm{n}=4-5$ each time point/tumor type). $\mathbf{g}-\mathbf{i}$ TaqMan analysis of the hypoxia responsive gene VEGF in Colo205, C6 and HT1080 tumors after 8, 24 and $72 \mathrm{~h}$ aflibercept treatment $(\mathrm{n}=3-4$

magnitude of the decrease in these genes correlated well with changes in tumor MVD. However, these gene expression changes did not correlate with long-term TGI. Further, changes in 'acute' gene expression, such as Esm1 and Nid2, which appear to reflect direct VEGF target genes [30-32], similarly did not correlate with long-term TGI following treatment with aflibercept. This latter finding suggests that VEGF inhibition within a tumor is a necessary but not sufficient determinant of efficacy of antiVEGF therapy. each time point/tumor type). All experiments were repeated at least twice; shown is an example experiment ( $n=4-5$ (hypoxia data) or $\mathrm{n}=3-4$ (TaqMan data) for each time point). Results shown represent means or mean \pm standard deviation (SD). $P<0.05^{*},<0.01^{* *}$, $<0.001 * * *,<0.0001 * * * *$ by 1 way-ANOVA with Bonferroni post hoc test (hypoxia IHC, each time point compared to control (0 time point); TaqMan data, each time point compared to control (0 time point))

Agents that target other angiogenic signaling pathways further confound the attempts to correlate MVD, vascular markers or indicators of VEGF signaling with anti-tumor effects. For example, in pre-clinical models, blockade of the angiogenic ligand Dll4 results in increased MVD [18, 33] and endothelial cell marker genes (data not shown), but inhibits tumor growth, thus clearly showing that MVD changes are not predictive of anti-angiogenic treatment efficacy. In the case of Dll4 inhibition, the newly formed tumor vascular structures are non-functional [18, 33]. 
Fig. 5 Changes in tumor perfusion, but not in MVD, $24 \mathrm{~h}$ after aflibercept treatment are predictive of long-term tumor growth inhibition. a Summary of aflibercept effects on longterm tumor growth and shortterm (up to $72 \mathrm{~h}$ ) MVD, gene expression, tumor perfusion and hypoxia. b Poor correlation between MVD changes $(30 \mu \mathrm{m}$ OCT sections; $\mathrm{n}=4-5$ each treatment group/tumor type) and long-term TGI ( $\mathrm{n}=5-7$ each treatment group/tumor type) in Colo205, C6, HT1080, MMT, A431 and LLC tumors. c Good correlation between tumor perfusion changes $(n=7-24$ each treatment group/tumor type) and long-term TGI ( $\mathrm{n}=5-7$ each treatment group/ tumor type) in Colo205, C6, HT1080, MMT, A431, LLC, 786-0 and PC-3 M tumors. All experiments were repeated at least twice; shown is an example experiment for tumor growth $(\mathrm{n}=5-7)$ and vessel density $(n=4-5)$ data along with combined data for tumor perfusion data $(n=7-24$ each treatment group/tumor type) a

Tumor growth
Vessel density
'Acute' gene changes
'Delayed' gene change
Perfusion
Hypoxia

b
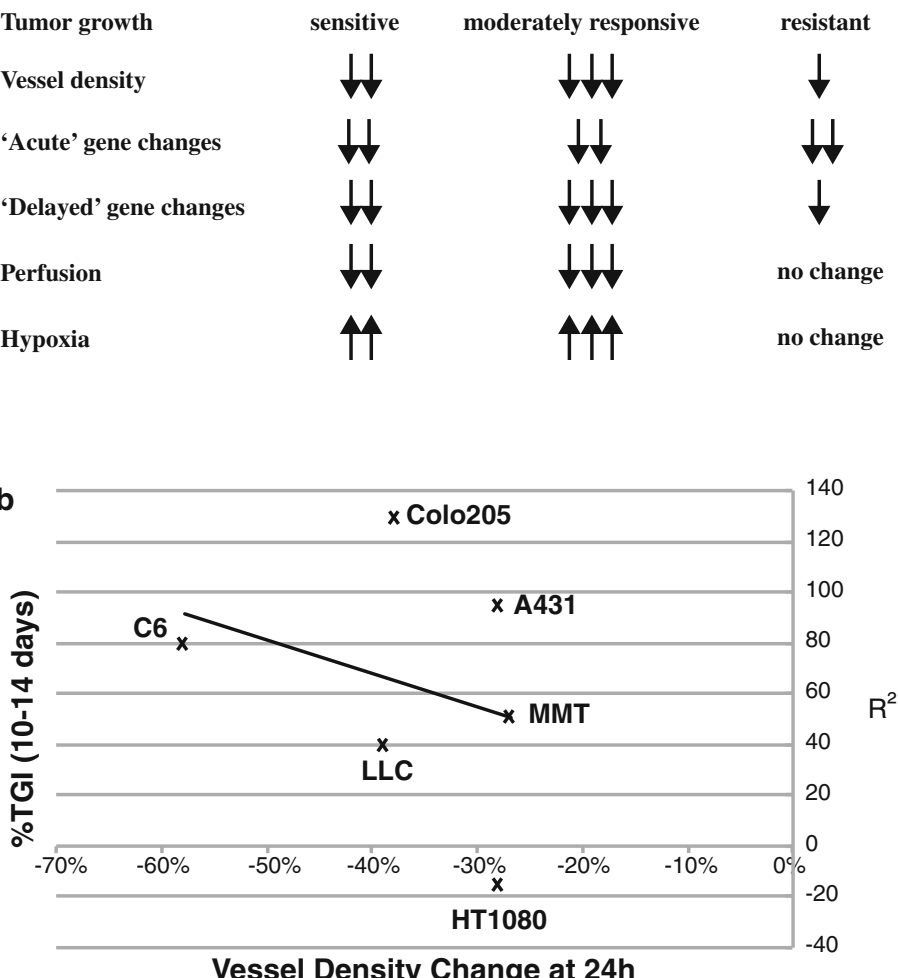

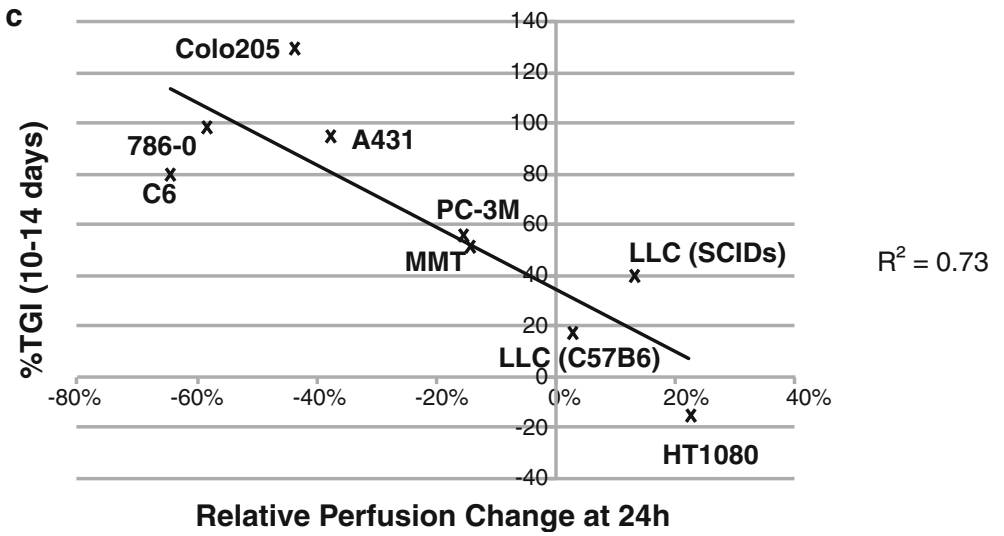

These findings, as well as our current results, emphasize the concept that changes in tumor vessel functionality are much more important for predicting tumor growth response than changes in the number of vessels, their morphology or their signaling profiles.

In preclinical models, intravenous injection of dyes like FITC-lectin, Hoechst 33342 or DiOC7 prior to sacrifice has frequently been used to distinguish perfused/functional vessels from non-perfused vessels in tissue sections [7, 19, 34-36]. In addition, FITC-lectin or Hoechst 33342 have been used with flow cytometry to detect perfused endothelial cells or to assess the ratio of tumor cells close to perfused blood vessels versus those further away [37, 38].
Our studies further validate the use of i.v. FITC-lectin combined with CD31 flow cytometry, to distinguish endothelial cells from perfused versus non-perfused vessels.

In clinical studies of VEGF blockade, DCE-MRI has been used frequently to evaluate the functional microvasculature within tumors. In particular, decreases in $\mathrm{K}^{\text {trans }}$, a volume transfer constant for contrast agent in blood/plasma and the extravascular extracellular space, was shown to be predictive of time to progression in liver cancer upon VEGF blockade [39]. Similarly, changes in $\mathrm{K}^{\text {trans }}$ allowed the prediction of responses in glioblastoma patients treated with bevacizumab and irinotecan [40]. In some preclinical tumor models, DCE-MRI has also revealed a decrease in 
$\mathrm{K}^{\text {trans }}$ in response to VEGF blockade [41]. However, DCEMRI was not predictive of treatment efficacy upon antiangiogenic therapy in other cancers, such as NSCLC [42]. In an attempt to better predict anti-angiogenic efficacy, DCE-MRI was combined with assessment of MVD and plasma collagen IV levels shortly ( $24 \mathrm{~h}$ ) after the start of treatment. This 'vascular normalization index', was predictive of responsiveness to anti-angiogenic therapy in glioma patients [43]. In a follow-up study, a prolonged increase in tumor perfusion, as evidenced by DCE-MRI, was associated with longer survival in glioma patients [44]. However, a recent positron emission tomography (PET) imaging study reported a decrease in perfusion and impaired docetaxel delivery after a single dose of bevacizumab in NSCLC patients [14], suggesting that vessel normalization after VEGF blockade does not occur in NSCLC. In another recent study, single-photon emission computed tomography (SPECT) imaging revealed that anti-VEGF treatment decreased tumor uptake of an antiHer2 antibody (trastuzumab) in preclinical breast cancer models, thus further supporting that VEGF blockade results in decreased tumor perfusion rather than vessel normalization [15].

In addition to DCE-MRI, PET and SPECT, other imaging modalities have been used to predict efficacy of anti-angiogenic therapies. For example, dynamic contrastenhanced ultrasound (DCE-US) imaging has been used to assess tumor perfusion before and after treatment of various cancers with anti-angiogenic agents [45-47]. DCE-US imaging typically uses gas-filled lipid-shell microbubbles several micrometers in diameter as contrast agent [48]. DCE-US differs from DCE-MRI in that it solely assesses changes in vascular perfusion, while DCE-MRI measures a combination of blood flow through the vasculature as well as tracer movement across the vessel wall [49]. Although DCE-MRI and DCE-US appear to have predictive potential in anti-angiogenic therapy, DCE-US may be less sensitive to changes in tumor vascular permeability, and thus be more robust for assessing changes in tumor perfusion.

Decreases in tumor perfusion can result in hypoxia, as was observed after aflibercept treatment of sensitive Colo205 and moderately responsive C6 tumors, but not in resistant HT1080 tumors. These findings can be compared to the vascular normalization hypothesis, which proposed that tumor vessels remaining after anti-VEGF therapy temporarily 'normalize' in terms of morphology and functionality, resulting in increased tumor blood flow and decreased hypoxia [10]. Other preclinical studies, however, have shown that the anti-angiogenic agents DC101 and AG-013736 induce decreased perfusion and increased hypoxia $[13,35,50]$. Although it is well established that human tumors are often hypoxic and poorly perfused [51], direct measurement of tumor oxygenation before and after
VEGF blockade in patients is challenging. Instead, hypoxia changes have been assessed indirectly. For example, bevacizumab treatment of RCC patients resulted in increased tumor cell apoptosis, along with increased tumor cell proliferation, which were hypothesized to be at least partially due to increased blood flow and decreased hypoxia [52].

The current study used various tumor models grown subcutaneously in mice, a site that can be readily accessed for micro-ultrasound studies of tumor perfusion. While the vascular structures and responses to anti-angiogenic therapies of such tumors may not fully reflect those of primary and metastatic human tumors, the ability to directly measure tumor blood flow provides opportunities to identify potential early response biomarkers that can be further tested in orthotopic preclinical tumor models and in clinical settings.

Early response biomarkers that can predict long-term outcome to therapy would be powerful tools, and panels of such potential biomarkers for anti-angiogenic therapies have been explored. For example, changes in circulating VEGF or PIGF levels, as well as tumor VEGF levels, were thought to be predictive, but to date have not shown to be well correlated with outcome [53]. In the current preclinical study, decreases in tumor perfusion and increases in hypoxia following treatment of subcutaneous xenograft and syngeneic models with aflibercept correlated with longterm TGI. Our results suggest that perfusion changes, as measured by DCE-US, shortly after treatment with VEGF inhibitors or possibly other anti-angiogenic therapies, could potentially be used as an early response biomarker to assess treatment efficacy.

Acknowledgments The authors would like to thank Alyx Rosen, Ivy Castro, Asma Parveen, Mihaela Gazdoiu, Kristin Vazzana and Pranitha Vangala for technical assistance, Ryan van Laar, Matthew Humes and Chiayi Kao for microarray/TaqMan assistance, Patricia Burfeind for flow cytometry assistance and Cristina Abrahams and all other members of the Thurston laboratory for critical comments and suggestions. Disclosure of potential conflicts of interest: All authors are current or former employees and shareholders of Regeneron Pharmaceuticals.

Open Access This article is distributed under the terms of the Creative Commons Attribution License which permits any use, distribution, and reproduction in any medium, provided the original author(s) and the source are credited.

\section{References}

1. Ferrara N (2009) VEGF-A: a critical regulator of blood vessel growth. Eur Cytokine Netw 20(4):158-163. doi:10.1684/ecn. 2009.0170

2. Duda DG, Batchelor TT, Willett CG, Jain RK (2007) VEGFtargeted cancer therapy strategies: current progress, hurdles and 
future prospects. Trends Mol Med 13(6):223-230. doi: 10.1016/j.molmed.2007.04.001

3. Grepin R, Pages G (2010) Molecular mechanisms of resistance to tumour anti-angiogenic strategies. J Oncol 2010:835680. doi: $10.1155 / 2010 / 835680$

4. Motzer RJ, Michaelson MD, Redman BG, Hudes GR, Wilding G, Figlin RA, Ginsberg MS, Kim ST, Baum CM, DePrimo SE, Li JZ, Bello CL, Theuer CP, George DJ, Rini BI (2006) Activity of SU11248, a multitargeted inhibitor of vascular endothelial growth factor receptor and platelet-derived growth factor receptor, in patients with metastatic renal cell carcinoma. J Clin Oncol 24(1):16-24. doi:10.1200/JCO.2005.02.2574

5. Escudier B, Eisen T, Stadler WM, Szczylik C, Oudard S, Siebels M, Negrier S, Chevreau C, Solska E, Desai AA, Rolland F, Demkow T, Hutson TE, Gore M, Freeman S, Schwartz B, Shan M, Simantov R, Bukowski RM (2007) Sorafenib in advanced clear-cell renal-cell carcinoma. N Engl J Med 356(2):125-134. doi:10.1056/NEJMoa060655

6. Llovet JM, Ricci S, Mazzaferro V, Hilgard P, Gane E, Blanc JF, de Oliveira AC, Santoro A, Raoul JL, Forner A, Schwartz M, Porta C, Zeuzem S, Bolondi L, Greten TF, Galle PR, Seitz JF, Borbath I, Haussinger D, Giannaris T, Shan M, Moscovici M, Voliotis D, Bruix J (2008) Sorafenib in advanced hepatocellular carcinoma. N Engl J Med 359(4):378-390. doi:10.1056/NEJMoa0708857

7. Inai T, Mancuso M, Hashizume H, Baffert F, Haskell A, Baluk P, Hu-Lowe DD, Shalinsky DR, Thurston G, Yancopoulos GD, McDonald DM (2004) Inhibition of vascular endothelial growth factor (VEGF) signaling in cancer causes loss of endothelial fenestrations, regression of tumor vessels, and appearance of basement membrane ghosts. Am J Pathol 165(1):35-52

8. Benjamin LE, Keshet E (1997) Conditional switching of vascular endothelial growth factor (VEGF) expression in tumors: induction of endothelial cell shedding and regression of hemangioblastoma-like vessels by VEGF withdrawal. Proc Natl Acad Sci U S A 94(16):8761-8766

9. Willett CG, Boucher Y, Di Tomaso E, Duda DG, Munn LL, Tong RT, Chung DC, Sahani DV, Kalva SP, Kozin SV, Mino M, Cohen KS, Scadden DT, Hartford AC, Fischman AJ, Clark JW, Ryan DP, Zhu AX, Blaszkowsky LS, Chen HX, Shellito PC, Lauwers GY, Jain RK (2004) Direct evidence that the VEGFspecific antibody bevacizumab has antivascular effects in human rectal cancer. Nat Med 10(2):145-147

10. Jain RK (2005) Normalization of tumor vasculature: an emerging concept in antiangiogenic therapy. Science 307(5706):58-62

11. Dickson PV, Hamner JB, Sims TL, Fraga CH, Ng CY, Rajasekeran S, Hagedorn NL, McCarville MB, Stewart CF, Davidoff AM (2007) Bevacizumab-induced transient remodeling of the vasculature in neuroblastoma xenografts results in improved delivery and efficacy of systemically administered chemotherapy. Clin Cancer Res 13(13):3942-3950. doi:10.1158/1078-0432. CCR-07-0278

12. Wildiers H, Guetens G, De Boeck G, Verbeken E, Landuyt B, Landuyt W, de Bruijn EA, van Oosterom AT (2003) Effect of antivascular endothelial growth factor treatment on the intratumoral uptake of CPT-11. Br J Cancer 88(12):1979-1986. doi: 10.1038/sj.bjc.6601005

13. Franco M, Man S, Chen L, Emmenegger U, Shaked Y, Cheung AM, Brown AS, Hicklin DJ, Foster FS, Kerbel RS (2006) Targeted anti-vascular endothelial growth factor receptor-2 therapy leads to short-term and long-term impairment of vascular function and increase in tumor hypoxia. Cancer Res 66(7):3639-3648. doi:10.1158/0008-5472.CAN-05-3295

14. Van der Veldt AA, Lubberink M, Bahce I, Walraven M, de Boer MP, Greuter HN, Hendrikse NH, Eriksson J, Windhorst AD, Postmus PE, Verheul HM, Serne EH, Lammertsma AA, Smit EF (2012) Rapid decrease in delivery of chemotherapy to tumors after anti-VEGF therapy: implications for scheduling of antiangiogenic drugs. Cancer Cell 21(1):82-91. doi:10.1016/j.ccr. 2011.11.023

15. Pastuskovas CV, Mundo EE, Williams SP, Nayak TK, Ho J, Ulufatu S, Clark S, Ross S, Cheng E, Parsons-Reponte K, Cain G, Van Hoy M, Majidy N, Bheddah S, Dela Cruz Chuh J, Kozak KR, Lewin-Koh N, Nauka P, Bumbaca D, Sliwkowski M, Tibbitts J, Theil FP, Fielder PJ, Khawli LA, Boswell CA (2012) Effects of Anti-VEGF on pharmacokinetics, biodistribution, and tumor penetration of trastuzumab in a preclinical breast cancer model. Mol Cancer Ther 11(3):752-762. doi:10.1158/15357163.MCT-11-0742-T

16. Batchelor TT, Duda DG, di Tomaso E, Ancukiewicz M, Plotkin SR, Gerstner E, Eichler AF, Drappatz J, Hochberg FH, Benner T, Louis DN, Cohen KS, Chea H, Exarhopoulos A, Loeffler JS, Moses MA, Ivy P, Sorensen AG, Wen PY, Jain RK (2010) Phase II study of cediranib, an oral pan-vascular endothelial growth factor receptor tyrosine kinase inhibitor, in patients with recurrent glioblastoma. J Clin Oncol 28(17):2817-2823. doi:10.1200/JCO.2009.26.3988

17. Rudge JS, Holash J, Hylton D, Russell M, Jiang S, Leidich R, Papadopoulos N, Pyles EA, Torri A, Wiegand SJ, Thurston G, Stahl N, Yancopoulos GD (2007) VEGF Trap complex formation measures production rates of VEGF, providing a biomarker for predicting efficacious angiogenic blockade. Proc Natl Acad Sci USA 104(47):18363-18370. doi:10.1073/pnas.0708865104

18. Noguera-Troise I, Daly C, Papadopoulos NJ, Coetzee S, Boland P, Gale NW, Lin HC, Yancopoulos GD, Thurston G (2006) Blockade of Dll4 inhibits tumour growth by promoting non-productive angiogenesis. Nature 444(7122):1032-1037. doi: 10.1038/nature05355

19. Eichten A, Hyun WC, Coussens LM (2007) Distinctive features of angiogenesis and lymphangiogenesis determine their functionality during de novo tumor development. Cancer Res 67(11): $5211-5220$

20. Ho M, Yang E, Matcuk G, Deng D, Sampas N, Tsalenko A, Tabibiazar R, Zhang Y, Chen M, Talbi S, Ho YD, Wang J, Tsao PS, Ben-Dor A, Yakhini Z, Bruhn L, Quertermous T (2003) Identification of endothelial cell genes by combined database mining and microarray analysis. Physiol Genomics 13(3):249262. doi:10.1152/physiolgenomics.00186.2002

21. Rodewald HR, Sato TN (1996) Tie1, a receptor tyrosine kinase essential for vascular endothelial cell integrity, is not critical for the development of hematopoietic cells. Oncogene 12(2):397-404

22. de Fougerolles AR, Stacker SA, Schwarting R, Springer TA (1991) Characterization of ICAM-2 and evidence for a third counter-receptor for LFA-1. J Exp Med 174(1):253-267

23. Woodfin A, Voisin MB, Nourshargh S (2007) PECAM-1: a multi-functional molecule in inflammation and vascular biology. Arterioscler Thromb Vasc Biol 27(12):2514-2523. doi:10.1161/ ATVBAHA.107.151456

24. Garlanda C, Dejana E (1997) Heterogeneity of endothelial cells. Specific markers. Arterioscler Thromb Vasc Biol 17(7):11931202

25. Gullino PM, Grantham FH (1961) Studies on the exchange of fluids between host and tumor. II. The blood flow of hepatomas and other tumors in rats and mice. J Natl Cancer Inst 27: 1465-1491

26. Weidner N, Carroll PR, Flax J, Blumenfeld W, Folkman J (1993) Tumor angiogenesis correlates with metastasis in invasive prostate carcinoma. Am J Pathol 143(2):401-409

27. de Jong D, Boot H, Taal B (2000) Histological grading with clinical relevance in gastric mucosa-associated lymphoid tissue (MALT) lymphoma. Recent Results Cancer Res 156:27-32

28. Borre M, Offersen BV, Nerstrom B, Overgaard J (1998) Microvessel density predicts survival in prostate cancer patients subjected to watchful waiting. Br J Cancer 78(7):940-944 
29. Hlatky L, Hahnfeldt P, Folkman J (2002) Clinical application of antiangiogenic therapy: microvessel density, what it does and doesn't tell us. J Natl Cancer Inst 94(12):883-893

30. Shin JW, Huggenberger R, Detmar M (2008) Transcriptional profiling of VEGF-A and VEGF-C target genes in lymphatic endothelium reveals endothelial-specific molecule- 1 as a novel mediator of lymphangiogenesis. Blood 112(6):2318-2326. doi: 10.1182/blood-2008-05-156331

31. Rennel E, Mellberg S, Dimberg A, Petersson L, Botling J, Ameur A, Westholm JO, Komorowski J, Lassalle P, Cross MJ, Gerwins $\mathrm{P}$ (2007) Endocan is a VEGF-A and PI3 K regulated gene with increased expression in human renal cancer. Exp Cell Res 313(7):1285-1294. doi:10.1016/j.yexcr.2007.01.021

32. Su SC, Mendoza EA, Kwak HI, Bayless KJ (2008) Molecular profile of endothelial invasion of three-dimensional collagen matrices: insights into angiogenic sprout induction in wound healing. Am J Physiol Cell Physiol 295(5):C1215-C1229. doi: 10.1152/ajpcell.00336.2008

33. Ridgway J, Zhang G, Wu Y, Stawicki S, Liang WC, Chanthery Y, Kowalski J, Watts RJ, Callahan C, Kasman I, Singh M, Chien M, Tan C, Hongo JA, de Sauvage F, Plowman G, Yan M (2006) Inhibition of Dll4 signalling inhibits tumour growth by deregulating angiogenesis. Nature 444(7122):1083-1087. doi:10.1038/ nature 05313

34. Trotter MJ, Chaplin DJ, Durand RE, Olive PL (1989) The use of fluorescent probes to identify regions of transient perfusion in murine tumors. Int J Radiat Oncol Biol Phys 16(4):931-934

35. Fenton BM, Paoni SF (2007) The addition of AG-013736 to fractionated radiation improves tumor response without functionally normalizing the tumor vasculature. Cancer Res 67(20):9921-9928. doi:10.1158/0008-5472.CAN-07-1066

36. Eichten A, Shen H-CJ, Coussens LM (2005) Three-dimensional visualization of blood and lymphatic vasculature in tissue whole mounts using confocal microscopy. In: Robinson JP (ed) Current protocols in cytometry, vol Suppl. 32. John Wiley \& Sons, Inc, New Jersey, pp 12.15.11-12.15.11

37. Sahagun G, Moore SA, Fabry Z, Schelper RL, Hart MN (1989) Purification of murine endothelial cell cultures by flow cytometry using fluorescein-labeled griffonia simplicifolia agglutinin. Am J Pathol 134(6):1227-1232

38. Chaplin DJ, Olive PL, Durand RE (1987) Intermittent blood flow in a murine tumor: radiobiological effects. Cancer Res 47(2): 597-601

39. Yopp AC, Schwartz LH, Kemeny NE, Gultekin D, Gonen M, Bamboat Z, Shia J, D'Angelica MI, DeMatteo RP, Jarnagin WR (2010) Dynamic contrast enhanced MRI (DCE-MRI) to measure antiangiogenic therapy and predict treatment response in primary liver cancer (PLC). J Clin Oncol (ASCO meeting abstract) 28 (suppl; abstr e14537)

40. Desjardins A, Barboriak DP, Herndon JE, Reardon DA, Quinn JA, Rich JN, Sathornsumetee S, Gururangan S, Friedman HS, Vredenburgh JJ (2007) Dynamic contrast-enhanced magnetic resonance imaging (DCE-MRI) evaluation in glioblastoma (GBM) patients treated with bevacizumab (BEV) and irinotecan (CPT-11). J Clin Oncol. ASCO Annual Meeting Proceedings Part I 25 (18S)

41. Checkley D, Tessier JJ, Wedge SR, Dukes M, Kendrew J, Curry B, Middleton B, Waterton JC (2003) Dynamic contrast-enhanced MRI of vascular changes induced by the VEGF-signaling inhibitor ZD4190 in human tumour xenografts. Magn Reson Imaging 21(5):475-482

42. Morgan B, Horsfield MA, Stattaus J, Khalil A, Gauler TC, Gounant V, Fischer B, Laurent D, Krissel H, Eberhardt WE (2007) Dynamic contrast-enhanced magnetic resonance imaging (DCE-MRI) as a biomarker for the effect of PTK787/ZK 222584
(PTK/ZK) as second-line mono-therapy in patients with stage IIIB or stage IV non-small cell lung cancer (NSCLC). J Clin Oncol. ASCO Annual Meeting Proceedings Part I 25 (18S)

43. Sorensen AG, Batchelor TT, Zhang WT, Chen PJ, Yeo P, Wang M, Jennings D, Wen PY, Lahdenranta J, Ancukiewicz M, di Tomaso E, Duda DG, Jain RK (2009) A “vascular normalization index" as potential mechanistic biomarker to predict survival after a single dose of cediranib in recurrent glioblastoma patients. Cancer Res 69(13):5296-5300. doi:10.1158/0008-5472.CAN09-0814

44. Sorensen AG, Emblem KE, Polaskova P, Jennings D, Kim H, Ancukiewicz M, Wang M, Wen PY, Ivy P, Batchelor TT, Jain RK (2012) Increased survival of glioblastoma patients who respond to antiangiogenic therapy with elevated blood perfusion. Cancer Res 72(2):402-407. doi:10.1158/0008-5472.CAN-112464

45. Lassau N, Koscielny S, Albiges L, Chami L, Benatsou B, Chebil M, Roche A, Escudier BJ (2010) Metastatic renal cell carcinoma treated with sunitinib: early evaluation of treatment response using dynamic contrast-enhanced ultrasonography. Clin Cancer Res 16(4):1216-1225. doi:10.1158/1078-0432.CCR-09-2175

46. Lassau N, Chami L, Koscielny S, Chebil M, Massard C, Benatsou B, Bidault S, Cioffi A, Blay JY, Le Cesne A (2010) Quantitative functional imaging by dynamic contrast enhanced ultrasonography (DCE-US) in GIST patients treated with masatinib. Invest New Drugs. doi:10.1007/s10637-010-9592-2

47. Lassau N, Chebil M, Chami L, Bidault S, Girard E, Roche A (2010) Dynamic contrast-enhanced ultrasonography (DCE-US): a new tool for the early evaluation of antiangiogenic treatment. Target Oncol 5(1):53-58. doi:10.1007/s11523-010-0136-7

48. Greis C (2009) Ultrasound contrast agents as markers of vascularity and microcirculation. Clin Hemorheol Microcirc 43(1):1-9. doi:10.3233/CH-2009-1216

49. Marcus CD, Ladam-Marcus V, Cucu C, Bouche O, Lucas L, Hoeffel C (2009) Imaging techniques to evaluate the response to treatment in oncology: current standards and perspectives. Crit Rev Oncol Hematol 72(3):217-238. doi:10.1016/j.critrevonc. 2008.07.012

50. Nakahara T, Norberg SM, Shalinsky DR, Hu-Lowe DD, McDonald DM (2006) Effect of inhibition of vascular endothelial growth factor signaling on distribution of extravasated antibodies in tumors. Cancer Res 66(3):1434-1445. doi:10.1158/00085472.CAN-05-0923

51. Willett CG, Duda DG, di Tomaso E, Boucher Y, Ancukiewicz M, Sahani DV, Lahdenranta J, Chung DC, Fischman AJ, Lauwers GY, Shellito P, Czito BG, Wong TZ, Paulson E, Poleski M, Vujaskovic Z, Bentley R, Chen HX, Clark JW, Jain RK (2009) Efficacy, safety, and biomarkers of neoadjuvant bevacizumab, radiation therapy, and fluorouracil in rectal cancer: a multidisciplinary phase II study. J Clin Oncol 27(18):3020-3026. doi: 10.1200/JCO.2008.21.1771

52. Willett CG, Boucher Y, Duda DG, di Tomaso E, Munn LL, Tong RT, Kozin SV, Petit L, Jain RK, Chung DC, Sahani DV, Kalva SP, Cohen KS, Scadden DT, Fischman AJ, Clark JW, Ryan DP, Zhu AX, Blaszkowsky LS, Shellito PC, Mino-Kenudson M, Lauwers GY (2005) Surrogate markers for antiangiogenic therapy and dose-limiting toxicities for bevacizumab with radiation and chemotherapy: continued experience of a phase I trial in rectal cancer patients. J Clin Oncol 23(31):8136-8139. doi: 10.1200/JCO.2005.02.5635

53. Otrock ZK, Hatoum HA, Musallam KM, Awada AH, Shamseddine AI (2011) Is VEGF a predictive biomarker to anti-angiogenic therapy? Crit Rev Oncol Hematol 79(2):103-111. doi: 10.1016/j.critrevonc.2010.07.008 